\title{
An Asymptomatic Patient with Severe Airway Obstruction
}

\author{
Lynn Decoster ${ }^{\mathrm{a}}$ Els Michiels ${ }^{\mathrm{c}}$ Eric Verbeken ${ }^{\mathrm{b}}$ Marc Decramer $^{\mathrm{a}}$ \\ Christophe Dooms ${ }^{\mathrm{a}}$
}

Departments of a Pulmonology and ${ }^{b}$ Pathology, University Hospitals Leuven, Leuven, and ${ }^{\mathrm{c}}$ Department of Pulmonology, Hospital Oost-Limburg, Genk, Belgium

A 44-year-old man was referred by his occupational physician because of a progressive decline in forced expiratory volume in $1 \mathrm{~s}\left(\mathrm{FEV}_{1}\right)$ detected at an annual medical check-up. The patient was a former smoker, with a 25 pack-year smoking history. He quit smoking 2 years ago. He was known to have an IgE-mediated allergy to grass and tree pollen with an associated oral allergy syndrome to stone fruits. He denied any respiratory symptoms and had an excellent exercise capacity (swimming $2 \mathrm{~km}$ twice a week). Clinical examination was non-remarkable. Spi-

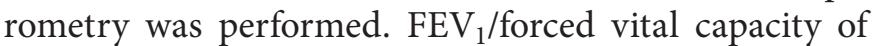
$34 \%$ and $\mathrm{FEV}_{1}$ of 1.67 liters or $48 \%$ of predicted confirmed severe airway obstruction. Peak expiratory flow was $5.131 /$ s or $59 \%$ of predicted. There was no significant reversibility after bronchodilation with salbutamol. Static lung volumes and diffusion capacity for carbon monoxide were within the normal range. The flow-volume (FV) loop is shown in figure 1.

What is your diagnosis?

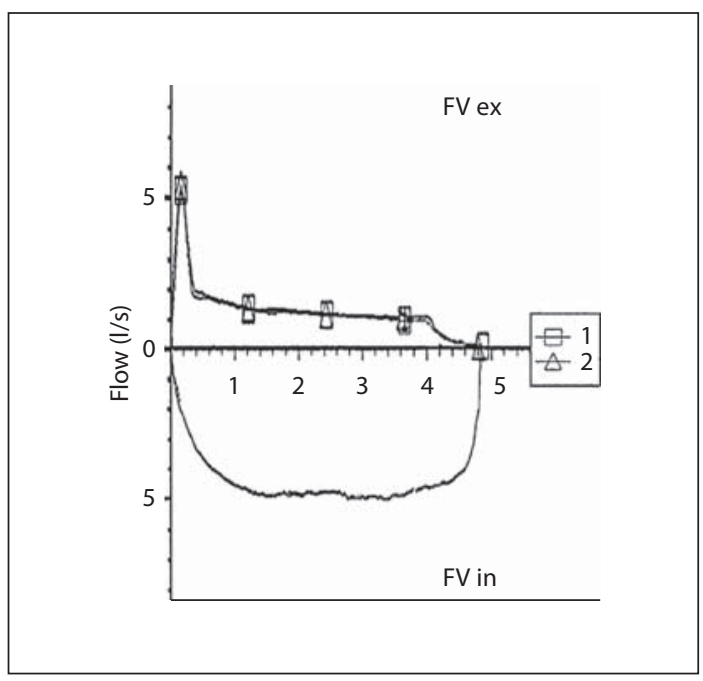

Fig. 1. FV curve showing severe airway obstruction.

\section{KARGER}

Fax +41613061234

E-Mail karger@karger.ch

www.karger.com
(C) 2010 S. Karger AG, Basel

0025-7931/11/0812-0157\$38.00/0

Accessible online at: www.karger.com/res
Christophe Dooms, MD, $\mathrm{PhD}$

Department of Pulmonology

University Hospitals Leuven

Herestraat 49, BE-3000 Leuven (Belgium)

Tel. +32 16346 802, Fax +32 16346 803, E-Mail christophe.dooms@uzleuven.be 

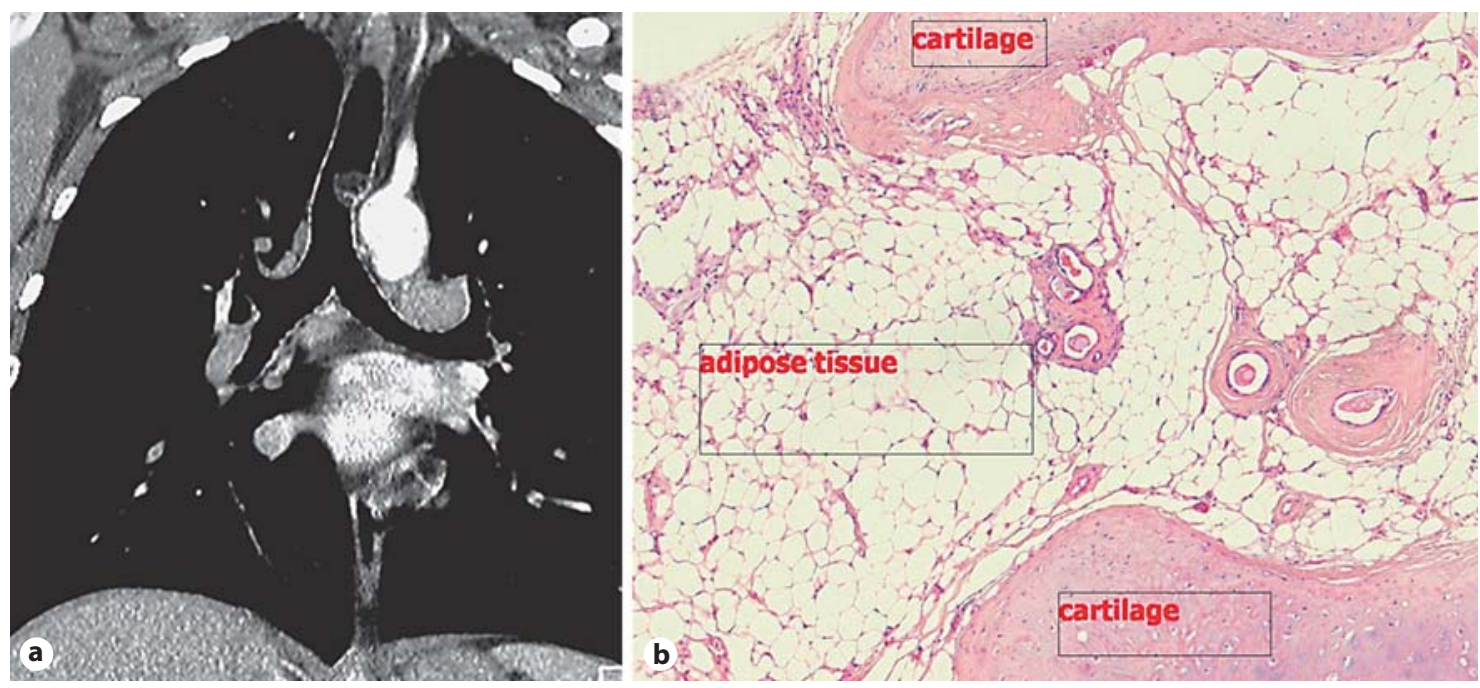

Fig. 2. a Coronal section of the chest CT showing a mass containing fat on the left lateral wall of the mid-trachea. b Histopathology of the bronchial biopsy specimen showing cartilage and adipose tissue in a disorderly fashion. $\mathrm{HE} \times 50$.

At first glance, the expiratory loop of the FV curve seems to have the typical dog leg appearance as seen in small-airway diseases such as chronic obstructive pulmonary disease (COPD). However, a plateau of the curve can be noticed after initial airway collapse occurring at peak expiratory flow. Furthermore, the FV curve also shows a flattening of the inspiratory loop. A fixed upperairway obstruction (UAO) was therefore suspected, and a CT scan of the chest and bronchoscopy were performed. The CT demonstrated a tracheal mass of $1.5 \times 1.5 \times 1.3$ $\mathrm{cm}$ in diameter, arising from the left lateral wall of the trachea $3 \mathrm{~cm}$ above the main carina. The lesion contained fat and foci of calcifications on CT (fig. 2a). Bronchoscopy confirmed the presence of a smooth, vascularized and pedunculated tumor on the left lateral tracheal wall, at the level of the aortic arc, occluding $80 \%$ of the airway lumen. The tumor was elastic in nature and very difficult to biopsy. Pathological examination demonstrated cartilaginous areas intermixed with adipose tissue, seromucinous glands and focal areas of calcification in a disorderly fashion (fig. 2b). The diagnosis of a tracheal hamartoma was made. Rigid bronchoscopy with laser treatment and tumor debulking largely restored airway patency. The FV curve returned to normal after the endoscopic treatment. There were significant increases in $\mathrm{FEV}_{1}$ (3.64 liters or $104 \%$ of predicted) and peak expiratory flow (8.34 1/s or $97 \%$ of predicted).

\section{Discussion}

We present a case that is remarkable in two aspects: (1) the apparent resemblance between the FV curve in our patient with UAO and the typical FV curve seen in obstructive lung diseases such as COPD, and (2) the unusual location of the hamartoma in the trachea (only $1 \%$ of all hamartomas).

At first glance, the FV loop of our patient with tracheal stenosis (fig. 3a) mimics the FV loop of COPD (fig. 3b) based on the peak expiratory flow reached, followed by expiratory airway collapse [1]. However, airway collapse occurs at a higher expiratory flow in UAO compared to COPD (fig. 3a, b: full line). Secondly, one can notice a plateauing of the curve after initial airway collapse in UAO (fig. 3a: dashed line) rather than the slow progressive decline in expiratory flow at lower lung volumes that is normally seen in small-airway obstructive lung disease (fig. 3b: dashed line). Finally, the inspiratory FV loop reaches a higher inspiratory flow in COPD (fig. 3b: dotted line) compared to plateauing at a lower inspiratory flow in tracheal stenosis (fig. 3a: dotted line) [2]. After endoscopic treatment, the FV curve returned to normal (fig. 3c), which is clearly not the case after bronchodilation in end-stage COPD (fig. 3d).

A pulmonary hamartoma contains tissue components normally found in the lung, such as epithelial tissue and 
Fig. 3. FV curves of our patient with a tracheal hamartoma (a), a patient with endstage COPD (b) and our patient after endoscopic treatment (c). d Bronchodilator effect on the FV curve of a patient with end-stage COPD.

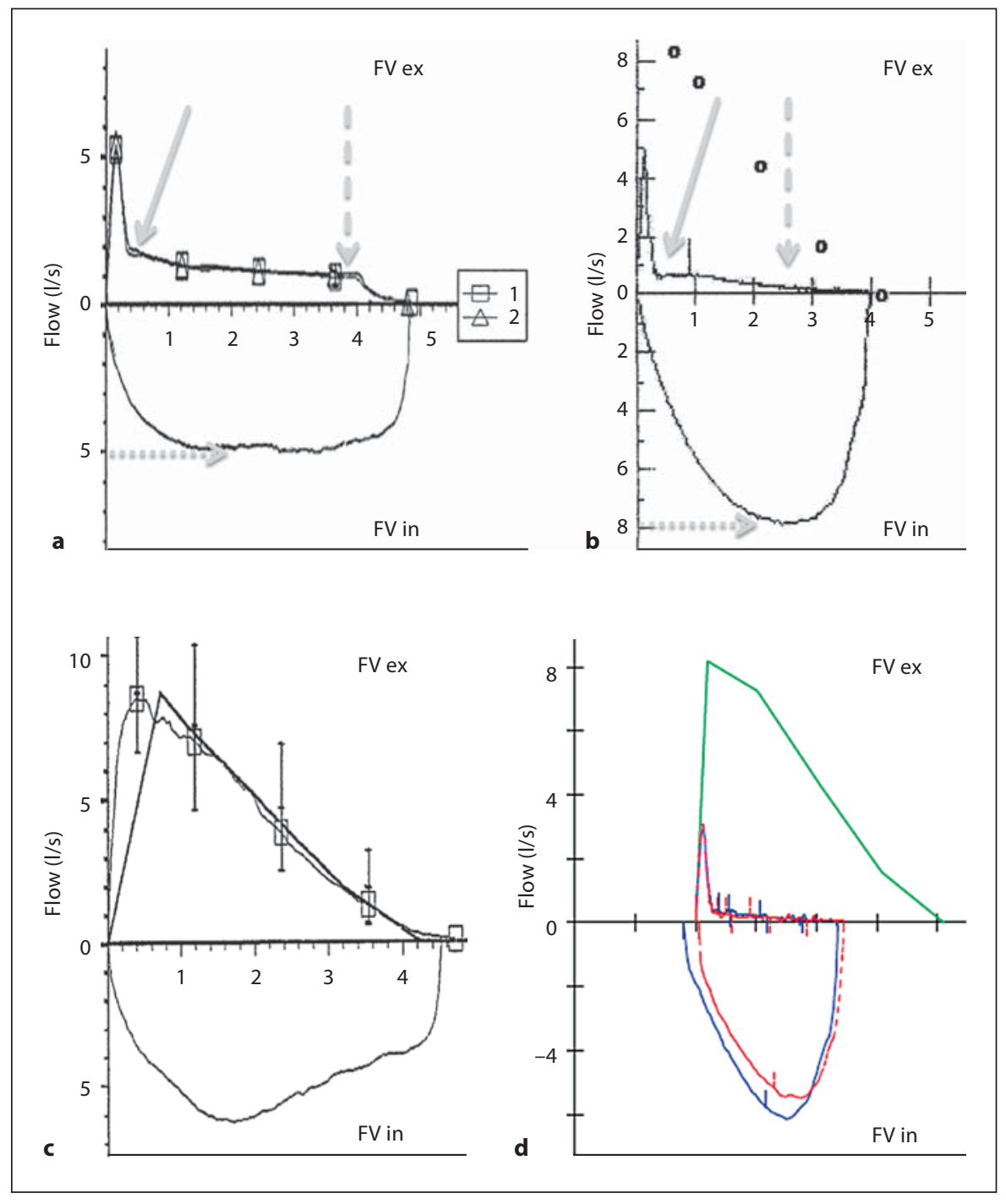

mesenchymal tissue (bone, cartilage, fat and fibrous tissue), which exhibit a disorganized growth pattern to result in a benign neoplasm. The exact etiology of hamartomas is unknown [3]. A distinction can be made between parenchymal and endobronchial hamartomas. Only $10 \%$ of hamartomas are located within the central airways and most of these centrally located hamartomas are found in the small (lobar and segmental) bronchi [46]. In the largest published series on hamartomas within the central airways, only $8.5 \%$ were located in the trachea [6]. Clinical presentation depends on the location and the size of the lesion. Most parenchymal hamartomas are asymptomatic and discovered incidentally on a routine chest X-ray, whereas endobronchially located lesions may cause symptoms of airway obstruction such as wheezing, cough, dyspnea, fever or stridor [6-8]. Hamartomas of the central airways may be diagnosed on CT scan, as the presence of fat is considered diagnostic of this entity [9]. Upon bronchoscopy, endobronchial hamartomas appear as tan to pink, smooth, fleshy, rounded or polypoid tumors, sometimes pedunculated. Bronchoscopy allows tissue sampling to confirm the diagnosis by histopathological examination. At biopsy, they may feel soft or hard, depending on the amount of cartilage tissue [10]. Although hamartomas are benign tumors with a low risk of malignancy and a low recurrence rate, endobronchially located hamartomas may require treatment because they cause obstructive symptoms or bleeding. In a retrospective series of 17 patients with endobronchial hamartoma, 15 patients were treated with bronchoscopic resection without any procedure-related morbidity or mortality [6]. 


\section{References}

$>1$ Bass H: The flow volume loop: normal standards and abnormalities in chronic obstructive pulmonary disease. Chest 1973;63:171176.

$>2$ Lunn WW, Sheller JR: Flow volume loops in the evaluation of upper airway obstruction. Otolaryngol Clin North Am 1995;28:721729.

3 Hodges FV: Hamartoma of the lung. Chest 1958;33:43-51.
-4 Van den Bosch JM, Wagenaar SS, Corrin B, Elbers JR, Knaepen PJ, Westermann CJ: Mesenchymoma of the lung (so called hamartoma): a review of 154 parenchymal and endobronchial cases. Thorax 1987;42:790793.

5 Kim SA, Um SW, Song JU, Jeon K, Koh WJ, Suh GY, Jung MP, Kwon OJ, Park JH, Yi CA, Han J, Kim H: Bronchoscopic features and bronchoscopic intervention for endobronchial hamartoma. Respirology 2010;15:150 154.

6 Cosio BG, Villena V, Echave-Sustaeta J, de Miguel E, Alfaro J, Hernandez L, Sotelo T: Endobronchial hamartoma. Chest 2002;122: 202-205.
7 Diacon A, Bolliger C: Therapeutic bronchoscopy for treatment-resistant COPD. Respiration 2002;69:451.

8 Gjevre JA, Myers JL, Prakash UB: Pulmonary hamartomas. Mayo Clin Proc 1996;71: 14-20.

9 Reittner P, Muller NL: Tracheal hamartoma: CT findings in two patients. J Comput Assist Tomogr 1999;23:957-958.

10 Vaylet F: An uncommon endotracheal finding. Rev Mal Respir 1999;16:222-223. 